\title{
El Arte en el Señorío del Chimú
}

Probada la inutilidad de una dimensión unitaria en los grupos de las culturas norteñas, tenemos que recurrir a una división en períodos, así sea apoyándonos en una vaga relación cronológica. La Confederación Chimú vendría a ser el último eslabón de culturas de rápido crecimiento tropical y, por consiguiente, de temprana muerte. Su epígono cultural estable sería la antigua metrópoli de Chan-Chan, capital del "Señorío del Gran Chimú", federación de pueblos del litoral norte del Perú. ChanChan separa la historia del arte propiamente Chimú, del confuso pasado prehistórico del arte Muchik, Trujillo, Chicama, Cupisnique y otros nombres derivados de diferentes grados evolutivos de una misma cultura.

Las ruinas de la ciudad se levantan en la sequedad de una llanura de veinte kilómetros cuadradoścenancoaisajequedae la sensación de estar hecho de cenizas: murallas gigantescas tumbas y muros carcomidos por diez siglos de lluvias y de intemperie, mantienen todavía el plano de plazas, calles, pozos, andenes, terrazas y canales que un tiempo regaron jardines y sembríos. En medio de la parda arcilla las manchas bermejas de los hornos para siempre fríos. Por todas partes habitaciones y muros escalonados muestran el encaje de bajorrelieves planiformes, con hormigueante fantasía de pájaros, peces y hombres estilizados entre figuras geométricas que dan sorprendente vertiginosidad de movimiento a estas representaciones.

Las colosales construcciones hechas de greda mezclada y taloneada, y con adobes de todos tamaños y formas, cubiertos de fino estuco coloreado, han podido resistir a los sismos y al tiempo para transmitir el elocuente mensaje de su historia. "Las murallas todavía impuestas de ChanChan parecen delimitar otro mundo. Se desea permanecer entre ellas o huir experimentando alternativamente el afán o el miedo de irsə del 
planeta. Están en la Tierra, el mundo y están en adobes, las piedras, el ripio, los almocardes, los besantes y la fastuosa biblia de los huacos" (1).

La distribución del plan urbano, las grandes murallas que defienden la ciudad, los "barrios" y los subterráneos, atestiguan un alto grado de adelanto arquitectónico; el concepto griego de la Polis, resultado de un proceso social que vemos en pleno desenvolvimiento en el Imperio Incaico.

En Chan-Chan al mismo tiempo que el poder político y religioso se levanta el templo y la tumba, luego el palacio y la plaza, los andenes y los barrios: la ciudad con la organización del trabajo aprovechando los elementos dispersos por el litoral; el tributo como vínculo de unión y el artista como instrumento del sacerdote para dar unidad ideológica a la Inueva constelación sociológica dirigida por un soberano semidivino, empenachado y paternal: el Señor del Gran Chimú. Por la "biblia" de los huacos, por el mensaje de las tumbas, sabemos que éste es el jefe de una confederación de pueblos laboriosos: pescadores, cazadores, y, sobre todo, agricultores. El "señor dispone del suntuoso cofre de pasadas culturas en la abundancia del subsuelo histórico. Grandes tesoros con que enjoyarse y con que asegurar la vida estética de su pueblo. Miriadas de trabajadores preexistentes, expertos en el arte del bajorrelieve. para cubrir la ciudad entera, de tal manera que ninguna pared queda con espacios lisos. Todo se clubre deccolores y frisosen una ornamentación que revela un arte menor, de apretado parroquismo, que el pueblo chimú opone a la monotonía planilínea de la arquitectura, la llanura y el mar.

En la combinación decorativa de los muros, en la forma de los ceramios, en el suntuoso adorno del vestuario y la riqueza de las joyas, se patentiza el adelanto de una cultura primaria en diario culto a las fuerzas que deparan la vida, protegen las cosechas, conjuran las sequías, la muerte y las asechanzas de divinidades malignas. Y divinidades opuestas como el Dios Con, en forma de pez y de ave, creador de hombres y cosas, rey de los mares y del espacio. Chatay, el sol, con un séquito de dioses inferiores, ayudado por la luna, Quillapa Huillac, y un ejército de "gatos manchados", por el rugido del rayo en las altas cumbres de la sierra, por el Lucero de la Mañana y el Lucero de la Tarde - Achachi Ururi y Apadri Ururi- lucha cada aurora contra las tinieblas.

(1) José Gabriel. "Un viaje a Trujillo". "La Tribuna". 22 octubre 1947. 
El sunfuoso panteón chimú se completa con sacerdotes y brujos; con interpretadores de oráculos y sacrificadores; con yerbateros, curanderos y danzantes; con rogadores y oficiantes, músicos antaristas y quenistas y un mundo de cortesanos y parástitos agrupados alrededor de una teocracia absolutista.

La aparición de sacrificios anuncia el viraje de este pueblo pacífico hacia la conquista y las prácticas crueles. En el último período aparece la religión ligada a lo mágico-sincrético-fetichista. El mito truculento está de acuerdo con una organización sacerdotal que borra las huellas de la autoridad femenina, los rezagos del matriarcado que debió tener gran influencia. El palacio se transforma en fortaleza. El "Señor" se torna poderoso.

Chan-Chan es el gran horno donde se funden los diferentes períodos arquelógicos del litoral norte: Proto-Chimú, Chimú Medio, Chimú Nuevo, Tallan, etc. Toda la historia de los valles norteños está impresa en el encaje de sus muros. En el vuelo entrelazado de las aves, en el enlace de reptiles, mamíferos, peces y hombres. Muros y cámaras enteras de una ideografía indescfrable e indescifrada surgen en cada exploración, junto con nuevos elementos y nuevas sorprendentes representaciones. Y cada año son borradas por la incuria (2).

El último friso descubierto por el arqueólogo Max Díaz muestra una escenografía sin precedentes. Entre marcos paralelos, en juego de diagonales que convergen a un cuadro central, hecho también de frisos verticales, encontramos una figuración seminaturalista y geométrica formada con elementos americanos y griegos, en fantástico despliegue decorativo. Franjas de Jpájaros estilizadosi deliómbies' y de plantas entre el juego de ángulos y círculos, todo en movimiento y entre "grecas" del más puro linaje helénico. Si no hubiéramos asistido a su descubrimiento podríamos abrigar dudas sobre su origen antiquísimo.

El Dr. Valcárcel cree que la costumbre de colgar paños en las paredes originó las esculturas en bajorrelieve y la necesidad de adorno arquitectónico. Pero éstas y otras hipótesis no tienen bases muy sólidas, ya que encontramos decoraciones de idéntica calidad en los monumentos de Mitla, donde tienen, más bien, una significación religiosa. En Chan-Chan algunos frisos conservan aun los vivos colores de que, sin duda, estaban revestidos en lejanos tiempos.

(2) La Universidad de Trujillo acaba de tomar a su cargo la conservación de este monumento. Bajo la dirección del arqueólogo Max Día se siguen las excavaciones con los re-
queridos cuidados para la preservación de los nuevos descubrimientos. 
PARAMONGA.-Desde una época menos remota que Chan-Chan, cerca del río Pativilca, a cuatrocientos kilómetros de dístancia de la capital del Chimú, se levanta el santuario-fortaleza de Paramonga. Las puntas de sus muros en talud, sobre una colina de tierra arenosa, asoman sobre un mar de cañaverales.

Paramonga se aparta del rectanqulismo, con tendencia a lo colosal, de Chan-Chan. Tres cuerpos de terrazas forman este edificio de indudable carácter defensivo, según lo prueba un lado inaccesible que prolonga un ángulo saliente de murallas. Sobre la terraza superior todavía quedan restos de habitaciones y dependencias. Las paredes han ido desmoronándose, sepultando las graderías, los adoratorios, las "huacas"; haciendo confuso el plano arquitectónico; desbaratando las pinturas murales cuyos vestigios todavía quedan sobre el estuco.

Cuando los ejércitos de Pachacutec atacaron esta fortaleza (1450) fueron largas las horas de combate y los días de sitio. La pelea comenzaba al mismo itempo que "Chatay" con sus guerreros combatía a las tinieblas. Sobre el fondo violento de las murallas de Paramonga cubiertas con çolores indios: amaranto, rojo almagre y anaranjado, entre la verdura, se destacaban los grandes jefes de la Confederación Chimú, pesados de yelmos de alajena (mate), totems y máscaras, pectorales de oro, los turbantes violetas, las gruesas porras y las lanzas livianas, los escudos de mim. bre rellenos de algodón, los pendones con amuletos y signos brujos. Una visión poética de la lucha anotada por algunos cronistas nos señalan la fortaleza como un importantermonumento histórico. Hoy, despojada de galas y colores, al descubierto la arcilla de su muros ocres, en inútil mimetismo, defiende todavía su sentido de eternidad.

La mayor parte del arte chimú está dotado de un sentido ornamental que le resta profundidad. Quizá obedezca a un simbolismo pictográfico no descifrado aun. No soy ya los sondeadores metafísicos de Tiawanako ni los realistas moldeadores de la forma Mochik. Tampoco los intermedios Cupisniques, creadores de vasos policromados, globulares. Se ha apagado la antorcha de Chavín, y el felino ha dejado de ser encarnación de la deidad suprema. El Señorío reposa en fomidos guerreros y en sacerdotes prácticos en brujismo. Domina los valles fértiles que rodean Nepeña, Chicama, Trujillo, Virú y Chan-Chan. Los comerciantes van por el sur hasta los límites del Señorío Chincha, de donde traen telas bordadas. Pasan por Ancón para adquirir grandes tinajas mortuorias. Por el norte llegan hasta los candentes arenales de Piura, donde truecan algodón por cacao, adquieren muestras de "tumbagas" de Colombia y la joyería barroca de la costa de Esmeralda. Influenciados por 
estas relacionés vivas, los artistas chimús toman gusto por el material precioso. Se despreocupan de la arcilla demasiado frágil. Buscan en el oro, el bronce y la plata la realización de la forma. En las cumbres, donde sopla con mayor fuerza el viento, construyen huayras (hornos), forjan en metal pectorales, máscaras, orejeras, toda una joyería rotunda y suntuosa de impresionante fuerza bárbara y también de indiscutible refinamiento.

Les sirven de inspiración los motivos encintados de la cerámica Chavín; los incindidos de los cántaros Cupisniques, de aspecto pétreo y de color pardo, rojo y negrusco; el realismo del subsuelo histórico de los Mochik, la concepción geométrica de Tiawanako. De los ceramios los hacen pasar al metal duro en una adaptación imitativa, sin intervención creativa y sin modificaciones estilísticas. "Estos procedimienots demuestran la evolución de un estilo aceptando la imposición de distintos materiales en sus campos técnicos. Esta evolución puede ser representada por una flexibilidad que establece relaciones entre la piedra, el metal y los tjidos" (3).

Figuras de felinos, serpientes y escenas humanas se trasladan al mundo geométrico y naturalista de los Chimú elaboradas en oro, plata y "champi" (4). Cada obra de arte ha dejado impresa la huella de las raíces históricas, el sello inconfundible de una ideología más o menos remota. En las manos de los plateros chimús se enriquece de técnica y esplendor; en la de los ceramistas se empobrece por la industrialización y el uso del molde. Los plateros aportan algunos elementos decorativos personales; acentúan la interpretación naturalista en la lograda abstracción de la forma y, en procesol inversolilosoceramistas desnaturalizan la realización precisa del modelo. En todo hacen intervenir una fantasía exótica no exenta de calidad plástica y de gracia; un ritmo ingenuo que sólo puede dictar la naturaleza. Como hemos dicho, la producción se mecaniza, debido al empleo de distintos materiales y a los cambios técnicos. Esta evolución hace que la forma se limite. Los motivos zoomorfos, antro-zoomorfos, cefalomorfos y fitomorfos se repiten con abrumadora monotonía. Las vasijas negras de los tallanes y los cántaros coloreados de los Chimú, marcan una palpable decadencia. La simplificación plástica, la preocupación naturalista, sin mensaje del espíritu, resta calidad al arte. Despojados de fantasía, los mitos, se amarran a la tierra. Los atributos de la divinidad son tirados del suelo, del medio ambiente, de

(3) Jorge C. Muelle. "Concerning the midle Chimú Style". University of California. Press. Berkeley and Los Anqeles. 1943. Páq. 203.

(4) Metal hecho de una amalgama de cobre y oro. 
la costumbre social. No hay pasión ni drama en las escenas esculpidas por el ceramista chimú. Es arte utilitario, sin proligidad estética. Representación de hechos y de formas sin trascendencia. Frutas y legumbres: arracachas, ají, yucas, camotes, papas, calabazas, piñas, pacaes, conchas marinas, camarones, peces, reptiles. Gavilanes, buhos, cóndores, venados y llamas. Una variedad zoomorfa y fitomorfa reproducida con fidelidad de copia. Se sacrifica, si el caso lo requiere, la forma cómoda o util del cántaro en aras de la fidelidad objetiva.... Donde el escultor Chimú hace resaltar sus méritos es en la composición de escenas familiares, en lo pintoresco y anecdótico: llamas descansando, arrieros cargando sus bestias, faenas agrícolas y aspectos del trajín rutinario. En estas obras se puede apreciar la exactitud con que el artista ha logrado captar el movimiento, la actitud habitual. La vulgaridad naturalista se salva gracias al dinamismo que siempre imprimen a las personas y a las cosas, y que se opone tan decididamente al estatismo realista. Dan curiosa vida emotiva al animal cuando se rasca, rumia, anda o descansa. Al hombre en la faena, la danza o los pequeños incidentes del trabajo. El artista chimú no ensaya nunca lo trascendental ritológico. Se queda en los límites del magismo. Es un primitivo rodeado por un ambiente apacible, incapaz de perturbar la ingénita alegría de su acto creador. Los huacos-retratos heredados de los Muchik, se caricaturizan, pierden profundidad. Su capacidad de copiadores industriosos, su afán imitativo, los lleva a buscar facilidades téenicas, descubrir procedimientos para acercarse a la imitación de la naturaleza en juegos ingentosos. QSos "Huacos silbadores", ceramios que representane paiaros qublial verter reloagua producen algo parecido al trino de un ave, "demuestran que el prurito onomatopeico los lleva a imitar hasta el sonido de la naturaleza".

Sin embargo, hay regiones del Señorío que tienen ceramios de cierta alcurnia morfológica, con formas mentales que revelan, en el espacio tiempo estético chimú ciertas influencias extraordinarias, como los de Nepeña, superiores a la cerámica lisa, de color crema, con figuras en altorelieve de Chavín, o los rojos y negros de Virú, de figurillas agazapadas. en los éngulos de las asas.

En esta cerámica se representan hechos de querra, ceremonias, prisioneros mutilados. También hay escenas de la vida ceremonial fastuosa donde los jefes adornados con ricos atavíos, alternan con animales totémicos, principalmente el buho y la serpiente.

Los ceramios negros del Chira, límite norte del Señorío, son interesantes por su variada figuración, de forma generalmente esférica, de base redonda, del clásico gollete con picos tubulares unidos por un 
puente en forma estribada y color negro. La forma simple de las plantas y legumbres son las preferidas: guanábana, mamey, maíz, lúcuma, chirimoya.

\section{ORFEBRERIA CHIMU}

Donde el artista chimú demuestra pleno dominio sobre la materia y resuelta aplicación de su fantasía, es en los trabajos en metal. Eximios joyeros: soldadores, moldeadores, forjadores, laminadores, los orfebres chimus llevan el arte metalúrgico a un plano superior al barbarismo colombiano. El metal en manos chimús se hace flexible. Se presta a la suntuosidad planiforme del bajorrelieve y la delicada fantasía de la filigrana. El artista chimú sobrepasa la etapa primitiva del arte de la "Tumbaga" colombiana. Enlaza un realismo intenso a una prodigiosa imaginación. Fundición, cincelaado, tonalidad, bruñido, todo con. tribuye a la proporción armoniosa, a la riqueza y prestigio de la joya. "Los peruanos fueron los únicos que trabajaron la plata, el repujado y el baño de oro sobre cobre y sobre plata" (5)

Si los artistas muchiks superan a los chimús en el trabajo de arquitectura y cerámica, los chimus no tienen rival en cuanto a la joyería. Parece que la misma decadencia del pueblo impulsara la excelencia de las artes suntuarias. Pueblo comerciante y conquistador, hizo posible la comprensión de los eximios joyeros del Ecuador, de los temibles quimbayas - los chibchas de Colombia. La arcaica cultura Chavín también prestó su concurso lejano, contribuyendèia elstaCperfección En pulgadas de metal esculpen figuras de dioses, totems y ornamentos con un significativo sentido de la función decorativa de la línea, en una representación que, desgraciadamente, no llega a sentar una clara explicación del dato religioso o histórico.

Al mismo tiempo resuelven con gran habilidad difíciles problemas de técnica. El cuchillo de Yllimo nos da una idea de la perfección artística que pudieron alcanzar los delicados escultores chimús. Este artístico cuchillo fué encontrado en una tumba cerca de Lambayeque, donde estaban enterrados algunos altos dignatarios del Señorío. Es un arma de ejecución delicada, de lámina delgada, de diez y siete pulgadas de largo, terminada en forma de média luna; en la rica empuñadura está esculpida la figura del semi-dios Naylamp, adornada con una aureola de

(5) Dr. Rive y Créqui-Montfort, "Contribution a l'etude de l'archeologie et de la metallurgie colombiennes".-Jour de la Soc. des Amer. de Paris, Tomo XI (1914). 
ocho turquesas verdes; el peinado cae en dos bandas, como alas de pájaro, símbolo de poder divino y facultad para volar al cielo. En los adornos se hacen palpables extrañas influencias. Este cuchillo contiene los caracteres generales de la iconografía chimú y es prueba concluyente de que, tanto los Muchik como los Chimú, no merecen el calificativo de "pueblos crueles, dados a la práctica de sacrificios humanos (6).

Los orfebres chimúes hacen gala de su habilidad para usar metales diferentes, principalmente un juego de oro y plata en combinación con la obsidiana y otras piedras en armonioso cromatismo, en ritmo de planos, franjas alternando con motivos ornamentales, figuras de pájaros, peces y plantas en diferentes relieves. La versatilidad del artista chimú en esta clase de trabajos se muestra, sobre todo, en los muñecos con las diferentes partes del cuerpo separadas, móviles y de diverso metal: oro en la cara y manos, champi en los pies, brazos y piernas.

Cuando se trata de objetos repujados; el artista se propone resolver el difícil problema de colocar las figuras en línea sinuosa, en lugar de aprovechar la facilidad que ofrece la línea horizontal, como se usa en la cerámica.

La lámina de oro y plata, usada para fabricar las diademas y vasos, es tan delgada que parece de papel. Hacían ánforas enormes de variada forma, también vasos medianos $\mathrm{y}$ cónicos, con el borde reforzado por un doblez de donde se desprende el asa. Por lo general los vasos obedecen a un modelo común tencla offebrerít peruana. A veces varían según estén fabricados de pro, plata, champi o madera. "Jorge ruichlatili champi o mad

\section{MASCARAS}

En todos los pueblos primitivos existe la preocupación mimética por disfrazar emociones, exaltarlas, desfigurarlas $e$ inventarlas. No hay pueblo sobre la tierra que haya dejado de usar la máscara, ya sea en ceremonias religiosas o en la guerra. Es el íntimo deseo de desdoblamiento y de superación en el hombre. Desde la más remota antigüedad los artistas han expresado en las máscaras el poder de los totems, de los mitos, de los hechiceros, de los guerreros, en gestos de exaltación de la vida o de solemne quietud de la muerte.

Aunque la expresión de las máscaras chimús no logra provocar la emoción dramática, el terror de las máscaras mexicanas, de todos modos

(6) Pal Keleman. "Medieval American Art". Edit. Mac Millan. New York. 1943. 
el escultor no deja de ser un meritorio creador que realiza con plástica sencillez, en finísima lámina de oro o plata, una representación del rostro humano. En este arte se acerca al exotismo, sin complicaciones, que emplea en la orfebrería. Eso sí, en la máscara se deja llevar por exigencias rituales o por atributos indispensables del mito. El trabajo técnico se realiza con máxima simplicidad, de acuerdo con un modelo preestablecido. Láminas muy delgadas representan al hombre, buho, felino o mono en sereno gesto, la boca entreabierta, los ojos cerrados, los rasgos fisionómicos precisos. La máscara funeraria está generalmente salpicada de turquesas barrocas; a veces, en lugar de ojos figuran cabezas de mono y la boca muestra los dientes. Las máscaras hechas en oro y plata son usadas sobre la cara de la momia o en un muñeco o momia artificial que encarna el "otro yo" ataviado con el mismo despliegue suntuoso del arte funerario.

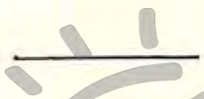

En la última parte de su historia el pueblo Chimú decae. Envilecido por la magia ignorante de los sacerdotes y el despotismo de los grandes señores, son conquistados por los incas. Al Cusco llevan su orfebrería para contribuir al esplendor del imperio del Tahuantinsuyo. Las joyas de alambre de oro retorcido serán ofrendas dignas de Wira Kocha. En la disciplina del ayllu el artista de Chan-Chan será maestro. El arte Chimu perderá su graciß sensualt hasta desaparecera en el molde severo de las artes del incanato.ge Puccinelli Converso»

F. COSSIO DEL POMAR. 